\title{
The COMT Val158 allele is associated with impaired delayed-match-to-sample performance in ADHD
}

\author{
Natasha Matthews ${ }^{1 * \dagger}$, Alasdair Vance ${ }^{2 \dagger}$, Tarrant D R Cummins ${ }^{1}$, Joseph Wagner ${ }^{1}$, Amanda Connolly ${ }^{2}$, \\ Jacqueline Yamada ${ }^{2}$, Paul J Lockhart ${ }^{3}$, Ajay Panwar ${ }^{4}$, Robyn H Wallace ${ }^{4,5}$ and Mark A Bellgrove ${ }^{1}$
}

\begin{abstract}
Background: This study explored the association between three measures of working memory ability and genetic variation in a range of catecholamine genes in a sample of children with ADHD.

Methods: One hundred and eighteen children with ADHD performed three working memory measures taken from the CANTAB battery (Spatial Span, Delayed-match-to-sample, and Spatial Working Memory). Associations between performance on working memory measures and allelic variation in catecholamine genes (including those for the noradrenaline transporter [NET1], the dopamine D4 and D2 receptor genes [DRD4; DRD2], the gene encoding dopamine beta hydroxylase $[\mathrm{DBH}]$ and catechol-O-methyl transferase [COMT]) were investigated using regression models that controlled for age, IQ, gender and medication status on the day of test.

Results: Significant associations were found between performance on the delayed-match-to-sample task and COMT genotype. More specifically, val/val homozygotes produced significantly more errors than did children who carried a least one met allele. There were no further associations between allelic variants and performance across the other working memory tasks.

Conclusions: The working memory measures employed in the present study differed in the degree to which accurate task performance depended upon either the dynamic updating and/or manipulation of items in working memory, as in the spatial span and spatial working memory tasks, or upon the stable maintenance of representations, as in the delay-match-to-sample task. The results are interpreted as evidence of a relationship between tonic dopamine levels associated with the met COMT allele and the maintenance of stable working memory representations required to perform the delayed-match-to-sample-task.
\end{abstract}

Keywords: Attention-deficit-hyperactivity-disorder, Working memory, COMT

\section{Background}

Attention-deficit/hyperactivity disorder (ADHD) is a common neuropsychiatric disorder, characterized by age-inappropriate symptoms of inattention, motor overactivity and impulsiveness, observed before the age of seven [1]. The disorder has an estimated prevalence of $3-8 \%$ in school-aged children [2] and causes significant lifetime academic, social and occupational impairment

\footnotetext{
* Correspondence: natasha.leigh.matthews@gmail.com

${ }^{\dagger}$ Equal contributors.

${ }^{1}$ The University of Queensland, Queensland Brain Institute and School of Psychology, St Lucia 4072 Brisbane, Australia

Full list of author information is available at the end of the article
}

[3]. Family, twin and adoption studies suggest a significant genetic contribution to ADHD, with heritability estimates between 70-90\% [4]. Despite this strong genetic loading mapping specific genes has proven difficult, in part due to the heterogeneous clinical presentation of ADHD. It has recently been proposed that cognitive endophenotypes, such as working memory ability, may increase the ability to detect subtle genetic effects by providing an index of neurobiological processes that are more closely related to the products of gene expression than diagnostic categories [5].

Working memory enables the temporary maintenance, updating and manipulation of relevant information in a

\section{Biomed Central}


limited capacity cognitive system and has a significant genetic component, with heritability estimates ranging from 33-49\% [6]. Working memory processes have long been implicated in theoretical models of ADHD and a growing literature confirms the robust nature of working memory deficits in the disorder [7].

Given that working memory ability permits internal representations of information to guide decision-making and behaviour, impairments in working memory are likely to have important functional consequences for many higher-order processes including language, planning and goal-directed behaviour [8]. Consequently, measures of impaired executive function, including working memory, have been linked to increased risk for grade retention and decreased academic achievement in children with ADHD [9]. Understanding the genetic determinants of individual differences in working memory ability in children with ADHD may therefore have important prognostic value.

Working memory is sub-served by a broad neural network involving the ventrolateral and dorsolateral prefrontal cortices, the striatum and the inferior parietal lobes $[10,11]$. However, within this network there is mounting evidence for a critical role for the prefrontal cortex, particularly for visuospatial working memory [12]. Within the prefrontal cortex spatial working memory ability is strongly mediated by the catecholamines dopamine and noradrenaline with both displaying an inverted U-shaped function whereby either too much or too little of either will result in sub-optimal working memory performance $[13,14]$.

Given the sensitivity of working memory ability to catecholamine levels, genes affecting these systems in prefrontal cortex may have utility for explaining individual differences in working memory ability. One of the most widely studied genes of relevance to prefrontal cognition is the catechol-O-methyltransferase (COMT) gene. COMT produces an enzyme that breaks down catecholamines, thus clearing them from the synaptic cleft. COMT is the primary mechanism of dopamine clearance in prefrontal cortex [15], in part because other regulators of synaptic dopamine, such as the dopamine transporter (DAT) are sparse in this region. A single nucleotide polymorphism (SNP: known as Val158Met or rs4680) comprising a guanine (G) to adenine (A) mutation results in an amino acid substitution of methionine (met) for valine ( $\mathrm{val}$ ) in enzyme synthesis. The more thermostable val allele is associated with greater dopamine degradation and hence less synaptic dopamine than the less stable met allele [16]. This change in thermostability may have consequences for working memory ability. The val rather than the met allele has been associated with reduced prefrontal cortical activation in functional neuroimaging studies of verbal working memory in healthy adults [17], and with poorer working memory performance in both adult populations $[18,19]$ and in healthy children [20]. It is reasonable therefore to hypothesize that working memory deficits in ADHD could be underpinned, at least in part, by the increased turnover of prefrontal dopamine that is associated with the val variant. Nevertheless, further examination of other genes of the catecholamine system that could also influence working memory is now also warranted.

To date, studies investigating the COMT variant as a risk factor for ADHD have been inconclusive. The majority of family-based studies that have examined the COMT polymorphism in ADHD have found no significant association, while associations with both the met and val alleles have also been reported [21]. Only a few studies have specifically investigated the relationship between COMT genotype and cognitive variables in ADHD populations and the results are inconclusive [22-24].

One explanation for the lack of consistency reported in the ADHD literature might be the varied characteristics of the tasks used to assay prefrontal function. There is evidence that prefrontal cortical dopamine is particularly important in the updating and stabilization of representations in working memory [25]. We therefore hypothesized that any associations with COMT genotype would be most pronounced in tasks requiring the active maintenance of a stable representation rather than the dynamic updating and manipulation of items stored in working memory.

The present study explored working memory in children with ADHD across a number of tasks that differed in the demands they placed on the necessity for maintenance of a stable representation versus dynamically updating working memory representations. Moreover, here we focus on non-verbal working memory tasks as previous research has suggested larger effect sizes for spatial, as compared to verbal, working memory tasks in ADHD [7]. We also explored for the first time the relationship between working memory ability in ADHD and allelic variation across a range of catecholamine genes, including those for the noradrenaline transporter (NET1), the dopamine D4 and D2 receptor genes (DRD4; DRD2), the gene encoding dopamine beta hydroxylase $(\mathrm{DBH})$ and COMT. Each of these genes has been implicated as potentially increasing genetic susceptibility to ADHD or has been related to executive function ability [26] but, there has not been a systematic investigation of their association with spatial working memory phenotypes in a large ADHD cohort.

\section{Materials and methods \\ Participants}

One hundred and eighteen Caucasian children with ADHD (6-16 years; 101 males: Table 1) were recruited 
Table 1 Demographic and clinical data for children with ADHD $(n=118)$

\begin{tabular}{ll}
\hline Measure & Mean (SD) \\
\hline Age & 9.7 years (2.6) \\
Full scale IQ & $91.4(11.2)$ \\
Conners' ADHD Index score & $74.2(9.9)$ \\
Conners' Global Index Total score & $79.9(6.9)$ \\
Conners' DSM-IV Inattentive score & $72.6(8.4)$ \\
Conners' DSM-IV Hyperactive/Impulsive score & $81.4(8.5)$ \\
Conners' DSM-IV Total score & $79.2(8.4)$ \\
\hline
\end{tabular}

through a specialized clinic for ADHD located at the Royal Children's Hospital ( $\mathrm{RCH})$ in Melbourne, Australia. Participants were referred to this service by school support staff because of difficulties noted in the school classroom and/or playground. Ethics approval for the study was obtained from the Human Research Ethics Committees of the University of Queensland, and the Royal Children's Hospital Melbourne. Informed consent was obtained from the parents of all participants and where appropriate, from the participants themselves. ADHD diagnosis was determined using the parent version of the Anxiety Disorders Interview Schedule for Children (A-DISC [27]) according to DSM-IV criteria [1]. Two experienced psychiatrists reviewed all clinical diagnoses. Parents were required to complete the Conners' Parent ADHD rating Scale-Revised: Long Version (CPRS-R:L [28]), and children with ADHD were required to have a Global Index $\mathrm{T}$-score $>65$ for inclusion in the study (Table 1), symptom pervasiveness was established using teacher responses on the Teacher Report Form (TRF [29]). Ninety-two (78\%) children with ADHD met criteria for ADHD-combined type, eighteen (15.3\%) for inattentive type, and eight (6.8\%) for the hyperactive-impulsive type. Children were excluded if they had a co-morbid diagnosis of major depressive disorder. Sixty-six $(55.9 \%)$ of the participants met criteria for co-morbid conduct disorder and 28 (23.7\%) met criteria for oppositional defiant disorder. Participant IQ was assessed by the WISC-IV [30] (Table 1) and participants were excluded if they had an estimated full-scale IQ $\leq 70$, or if they had previously been diagnosed with impaired sensorimotor skills (Scored Developmental Neurological Examination [31]) or learning disabilities (WRAT 3 [32]).

Ninety-five $(80.5 \%)$ participants were medication free at the time of testing, including seventy-four (62.7\%) participants who were medication naive and twenty-one (17.7\%) who underwent a medication wash-out period of at least $24 \mathrm{~h}$ prior to the testing session. The remaining twenty-three (19.4\%) participants were on active medication at the time of testing.

\section{Stimuli and procedure}

Participants performed three measures of working memory from the Cambridge Neuropsychological Test Automated Battery (CANTAB): spatial working memory (SWM), spatial span (SP), and delayed-match-to-sample (DMTS). All CANTAB measures were presented on a high-resolution IBM colour monitor with a touch sensitive screen at a viewing distance of 0.5 meters. The CANTAB is a computerized battery of neuropsychological tests originally developed for use with normal and neurologically-impaired populations between the ages of four and ninety, and which has also been successfully applied to children and adolescents with ADHD [33]. The CANTAB working memory measures have been shown to have a substantial heritable component [34], suggesting that they are suitable phenotypes for genetic analysis.

\section{Spatial span}

Participants were presented with 10 boxes that served as spatial placeholders. On each trial a subset of the boxes flashed sequentially. Participants were required to reproduce the spatial sequence by touching the boxes on the screen in the order in which they were presented. The length of the test sequence was increased by one item contingent upon performance, up to a maximum of nine items. Maximum correct sequence length was defined as their spatial memory span.

\section{Spatial working memory}

On each trial of this task participants were presented with a number of coloured squares located at different spatial locations. In order to find a token, participants were required to engage in a self-guided search of the coloured squares by touching each square in turn to identify if it concealed a token. Each square contained only one token on a given trial. Returning to a location in which a token had already been found on a given trial was scored as a search error. The number of squares presented on each trial (the display set size) was increased throughout the task: 3, 4, 6 to 8 items. Search error score was calculated for each set size and summed to produce a total error score.

A strategy score was also defined as a measure of the consistency with which a search strategy was employed; this is estimated from the number of searches that start with the same location within each of the six-item and eight-item searches. A high score indicates low use of strategy.

\section{Delayed match to sample}

Participants were shown a complex visual pattern and were then required to select the identical pattern from among four possible response alternatives. The difficulty 
of the task was manipulated by varying the delay between the presentation of the test stimulus and the presentation of the four response stimuli $(0,4$, to $12 \mathrm{~s})$. A simultaneous matching condition was also included to control for perceptual deficits. Performance was defined as the percentage of correct responses.

\section{Genotyping}

Genotyping on saliva samples provided by participants was performed on ten single nucleotide polymorphisms (SNPs) in the genes for dopamine beta hydroxylase (DBH: rs1611115, rs2519152 [35-37]), the dopamine D2 receptor (DRD2: rs1800497, rs6277, rs1079596, rs2075654 [38]), DRD4 (rs1800955 [39]), the noradrenaline transporter (SLC6A2 or NET1: rs3785155, rs880711 [38]) and catechol-O-methyltransferase (COMT: rs4680 [24]). These markers were chosen based upon prior evidence of the SNP conferring risk to ADHD or to neurocognitive deficits in ADHD or upon functional evidence for the SNP and its theoretical link to working memory.

Genotyping of all SNPs was performed by the Australian Genome Research Facility (AGRF) using iPLEX GOLD chemistry with a Sequenom MassArray on an Autoflex Spectrometer. Genotyping failures were in the region of 4-6\% across the SNPs investigated.

\section{Genetic association analysis}

Permutation methods are considered the gold standard for multiple comparison correction because they provide unbiased type 1 error control while maintaining statistical power. Accordingly we used a single step permutation method to test for genetic associations with our task variables (Please see [40-42] for a full description of single step permutation methods). Briefly, the analysis described below was performed separately for each of the working memory variables for each task (Delayedmatch-to-sample, span, and spatial working memory) using Matlab (v. 2008a; http://www.mathworks.com/products/). For each genetic marker an association analysis between the task variable and genotype was performed using single-step additive, dominant, and recessive regression models that included age, gender, IQ, and medication status on the day of testing, as covariates. The absolute (unstandardised) beta value for the task variable was recorded (these values are hereafter referred to as the unshuffled test statistics). This was then followed by a single step permutation method in which each individual's index (the profile that is made up of their score on the task variable and their scores on all of the covariates) was shuffled multiple times relative to the genetic data. For each shuffled configuration of the data, an association analysis (as described above) was performed for every genetic marker and the maximal absolute value observed for the test statistic (beta) of the task variable across all genetic markers was recorded. This process was repeated 100,000 times and a list of the maximal beta values (one beta value per shuffle) was generated. The single-step permuted p-value for any given marker was then calculated as the fraction of maximal beta values that were greater than or equal to the absolute value of the unshuffled test statistic for the marker in question. The critical $\mathrm{p}$ value for all analyses was $0.05 / 9$ or .0056 (i.e., the single step corrected permutation value corrected for the number of tasks [3] and the number of genetic models [3]).

Genotype frequencies for each marker are presented in Table 2. The results of the association analysis for each working memory phenotype are presented in Table 3 and in Additional file 1: Tables S1-S3. All markers were in Hardy-Weinberg equilibrium.

\section{Results \\ Working memory phenotypes Spatial span}

Children with ADHD had a working memory span of approximately 5 items on the SP task $(M=4.7, S D=1.4)$. There were no significant associations between SP and genotype (Additional file 1: Table S1).

\section{Spatial working memory}

The average error rate for SWM across all display set sizes in the ADHD children was $50.35(S D=19.1)$. There was a significant main effect of display set size $F$ $(3,351)=660.85, p<0.01$, and post hoc analysis confirmed that this was due to a significant increase in search errors with increasing display set size ( $p$ 's $<0.05)$. The mean strategy score for the ADHD group was 37.51 $(S D=3.23)$.

There were no significant associations between any of the markers and total errors or strategy score (Additional file 1: Table S2).

\section{Delayed matched to sample}

The children with ADHD had correct responses of $87.95 \%(S D=14.17)$ on the simultaneous condition. A repeated measures ANOVA conducted on the delay conditions confirmed that there was a significant main effect of delay $F(2,232)=33.43, p<0.001$, with a significant difference in mean percentage correct responses between the 12 and both the 4 and $0 \mathrm{~s}$ delay conditions $(p$ 's $<0.05)$.

Association analyses were performed using the percent correct on the simultaneous condition and the percent correct averaged across all delay conditions $(M=61.51 \%$, $S D=16.69)$. There were no significant associations between any of the markers and performance on the simultaneous condition (Additional file 1: Table S3). 
Table 2 Genotype frequencies for the 10 SNPs investigated

\begin{tabular}{|c|c|c|c|c|c|}
\hline \multirow{2}{*}{$\begin{array}{l}\text { Gene } \\
\mathrm{NET}\end{array}$} & \multirow{2}{*}{$\begin{array}{l}\text { Polymorphism } \\
\text { rs880711 }\end{array}$} & \multirow{2}{*}{$\begin{array}{l}\begin{array}{l}\text { Allele } \\
\text { minor/major }\end{array} \\
A / G\end{array}$} & \multicolumn{2}{|c|}{$\begin{array}{l}\text { Genotype count } \\
\text { (percentage) }\end{array}$} & \multirow{2}{*}{$\begin{array}{l}\begin{array}{l}\text { Minor allele } \\
\text { frequency }\end{array} \\
0.18\end{array}$} \\
\hline & & & $\mathrm{A} / \mathrm{A}$ & $4(3.5)$ & \\
\hline & & & $\mathrm{G} / \mathrm{A}$ & $32(28.3)$ & \\
\hline & & & $\mathrm{G} / \mathrm{G}$ & 77 (68.1) & \\
\hline & rs3785155 & $\mathrm{A} / \mathrm{G}$ & $\mathrm{A} / \mathrm{A}$ & $2(1.8)$ & 0.14 \\
\hline & & & $\mathrm{A} / \mathrm{G}$ & $28(25)$ & \\
\hline & & & $\mathrm{G} / \mathrm{G}$ & $82(73.2)$ & \\
\hline \multirow[t]{12}{*}{ DRD2 } & rs1079596 & $\mathrm{T} / \mathrm{C}$ & $\mathrm{T} / \mathrm{T}$ & $2(1.8)$ & 0.15 \\
\hline & & & $C / T$ & $29(25.7)$ & \\
\hline & & & $\mathrm{C} / \mathrm{C}$ & $82(72.6)$ & \\
\hline & rs1800497 & $A / G$ & $A / A$ & $4(3.5)$ & 0.22 \\
\hline & & & $\mathrm{A} / \mathrm{G}$ & $42(37.2)$ & \\
\hline & & & $\mathrm{G} / \mathrm{G}$ & 67 (59.3) & \\
\hline & rs2075654 & $\mathrm{T} / \mathrm{C}$ & $\mathrm{T} / \mathrm{T}$ & $2(1.8)$ & 0.15 \\
\hline & & & $\mathrm{T} / \mathrm{C}$ & $29(25.7)$ & \\
\hline & & & $\mathrm{C} / \mathrm{C}$ & 82 (72.6) & \\
\hline & rs6277 & $\mathrm{G} / \mathrm{A}$ & $\mathrm{G} / \mathrm{G}$ & $24(21.2)$ & 0.47 \\
\hline & & & $\mathrm{A} / \mathrm{G}$ & $58(51.3)$ & \\
\hline & & & $\mathrm{A} / \mathrm{A}$ & $31(27.4)$ & \\
\hline \multirow[t]{6}{*}{$\mathrm{DBH}$} & rs1611115 & T/C & $\mathrm{T} / \mathrm{T}$ & $9(8.0)$ & 0.27 \\
\hline & & & $\mathrm{T} / \mathrm{C}$ & $43(38.1)$ & \\
\hline & & & $\mathrm{C} / \mathrm{C}$ & $61(54)$ & \\
\hline & rs2519152 & $\mathrm{C} / \mathrm{T}$ & $\mathrm{C} / \mathrm{C}$ & $25(22.3)$ & 0.44 \\
\hline & & & $\mathrm{T} / \mathrm{C}$ & 49 (43.8) & \\
\hline & & & $\mathrm{T} / \mathrm{T}$ & 38 (33.9) & \\
\hline \multirow[t]{3}{*}{ DRD4 } & rs1800955 & $\mathrm{C} / \mathrm{T}$ & $\mathrm{C} / \mathrm{C}$ & $20(18)$ & 0.46 \\
\hline & & & $\mathrm{T} / \mathrm{C}$ & $62(55.9)$ & \\
\hline & & & $\mathrm{T} / \mathrm{T}$ & $29(26.1)$ & \\
\hline \multirow[t]{3}{*}{$\mathrm{COMT}^{*}$} & rs4680 & $\mathrm{G} / \mathrm{A}$ & $\mathrm{G} / \mathrm{G}$ & $25(22.1)$ & 0.44 \\
\hline & & & $\mathrm{G} / \mathrm{A}$ & 49 (43.3) & \\
\hline & & & $\mathrm{A} / \mathrm{A}$ & 39 (34.5) & \\
\hline
\end{tabular}

* For the COMT SNP ' $G$ ' refers to the 'Val' allele and ' $A$ ' refers to the 'Met' allele

Percentage of correct responses across delay conditions was significantly associated with COMT genotype under a recessive model at the corrected level $(p=0.0033)$ (Table 3). As shown in Figure 1 individuals with the $\mathrm{val} / \mathrm{val}$ genotype had the lowest accuracies overall $(M=51.67 \%, \quad S D=15.56)$, with $\mathrm{val} / \mathrm{met}$ $(M=65.67 \%, S D=17.67)$ and $\mathrm{met} / \mathrm{met}(M=60.67 \%, S D=$ $14.83)$ individuals performing similarly.

\section{Discussion}

A robust literature demonstrates that working memory ability is impaired in individuals with ADHD [7].
Working memory is known to be reliant upon prefrontal catecholamine levels [14], with COMT being an important regulator of this system [15]. Here, for the first time in children with ADHD, we explored the relationship between allelic variation in a broad set of catecholamine genes, including COMT, and measures of working memory.

In children with ADHD there was a significant relationship between COMT genotype and performance on the DMTS task. Val/val homozygotes had lower percent correct scores compared to those who carried at least one met allele. There was no relationship between COMT genotype and any of the other working memory

Table 3 The influence of common genetic variations on percentage correct for the DMTS task

\begin{tabular}{|c|c|c|c|c|}
\hline Gene & Polymorphism & Model & $\begin{array}{l}\text { p-value } \\
\text { (obtained) }\end{array}$ & $\begin{array}{l}\text { p-value } \\
\text { (corrected) }\end{array}$ \\
\hline \multirow[t]{6}{*}{ NET } & rs880711 & Dominant & 0.526 & 0.997 \\
\hline & & Recessive & 0.047 & 0.868 \\
\hline & & Additive & 0.868 & 1.000 \\
\hline & rs3785155 & Dominant & 0.504 & 0.997 \\
\hline & & Recessive & 0.002 & 0.824 \\
\hline & & Additive & 0.833 & 1.000 \\
\hline \multirow[t]{12}{*}{ DRD2 } & rs1079596 & Dominant & 0.309 & 0.952 \\
\hline & & Recessive & 0.975 & 1.000 \\
\hline & & Additive & 0.361 & 0.993 \\
\hline & rs1800497 & Dominant & 0.609 & 0.999 \\
\hline & & Recessive & 0.861 & 1.000 \\
\hline & & Additive & 0.615 & 1.000 \\
\hline & rs2075654 & Dominant & 0.309 & 0.952 \\
\hline & & Recessive & 0.975 & 1.000 \\
\hline & & Additive & 0.361 & 0.993 \\
\hline & rs6277 & Dominant & 0.695 & 1.000 \\
\hline & & Recessive & 0.716 & 0.999 \\
\hline & & Additive & 0.642 & 0.999 \\
\hline \multirow[t]{6}{*}{$\mathrm{DBH}$} & rs1611115 & Dominant & 0.249 & 0.850 \\
\hline & & Recessive & 0.825 & 1.000 \\
\hline & & Additive & 0.325 & 0.945 \\
\hline & rs2519152 & Dominant & 0.915 & 1.000 \\
\hline & & Recessive & 0.322 & 0.813 \\
\hline & & Additive & 0.536 & 1.000 \\
\hline \multirow[t]{3}{*}{ DRD4 } & rs1800955 & Dominant & 0.664 & 1.000 \\
\hline & & Recessive & 0.720 & 1.000 \\
\hline & & Additive & 0.612 & 1.000 \\
\hline \multirow[t]{3}{*}{ COMT } & rs4680 & Dominant & 0.291 & 0.921 \\
\hline & & Recessive & 0.00078 & 0.0033 \\
\hline & & Additive & 0.012 & 0.039 \\
\hline
\end{tabular}




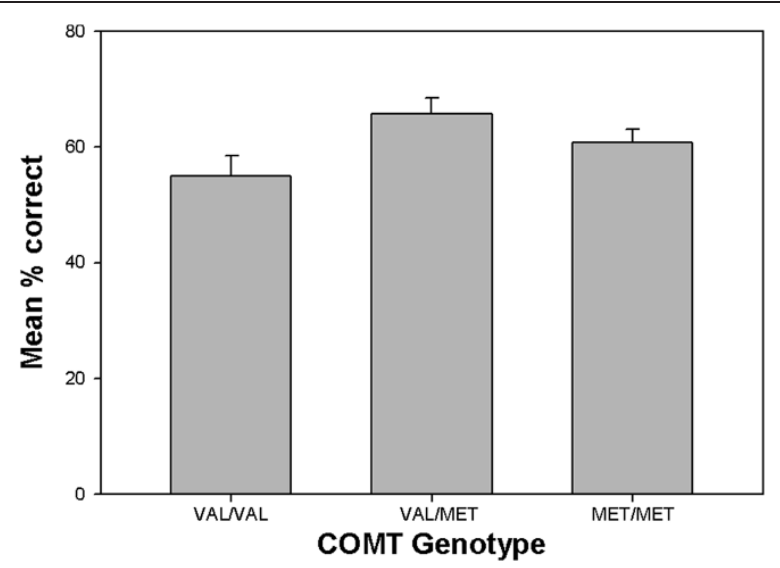

Figure 1 Mean percentage correct performance averaged across 0,4 , and $12 \mathrm{~s}$ delay conditions in the delayed-match-tosample task (adjusted for age, IQ, gender, and medication status) as a function of COMT genotype. Error bars represent standard error of the mean.

measures investigated. Performance on a working memory task requires the co-ordination of a number of abilities: information must be accurately encoded into working memory, maintained and/or manipulated depending on task demands, and finally retrieved. COMT genotype may be related to one or more of these subprocesses in children with ADHD.

Bruder et al. [43] investigated the relationship between COMT genotype and performance on a number of working memory tasks in a healthy adult population. They found that COMT genotype was related to performance on a Letter-Number Sequencing Task, but not to performance on a Spatial Delayed Response task, nback task, or Wisconsin Card Sorting Task. The authors argued that the Letter-Number Sequencing task was more taxing of executive processes and thus, that COMT genotype is more closely related to the manipulation of items in working memory than to maintenance.

The present results suggest an alternative interpretation; here there was an association between COMT and performance on the DMTS task, which relies on successful working memory maintenance, but not with the SP or SWM tasks, which place greater executive demands on the updating and manipulation of items. Within the DMTS task there was no interaction between COMT genotype and increasing working memory delay, suggesting that COMT genotype was not related to task difficulty. Similarly, there was no relationship between COMT genotype and performance on the simultaneous matching condition of the DMTS task, which provides a measure of perceptual accuracy. Therefore, it may be concluded that the relationship between COMT genotype and DMTS performance may be most sensitive to either impairments in the encoding of a stable representation into working memory or in retrieval stages.

One potential explanation for our pattern of results may be found in the tonic-phasic hypothesis of dopamine regulation [44]. According to this hypothesis dopamine action is orchestrated through the co-ordination of tonic and phasic states. The COMT met allele increases tonic dopamine transmission, which regulates the stability of cortical activation states. Tonic dopamine stimulation has thus been hypothesized to be important for maintaining stable representations in working memory. In contrast, phasic dopamine stimulation regulates the plasticity of activation states and is believed to be important for updating and manipulating working memory representations. Our findings are consistent with the role of the met allele in enhancing the stability and maintenance of representations required for performance on the DMTS task. These findings suggest that the determining factor in observing associations between neurocognitive measures and COMT genotype may depend more on the nature of the representation required to perform the task, rather than, as suggested by Bruder et al. [43], the executive load of the task per se.

Interestingly, both chronic and acute administration of methylphenidate, a stimulant drug that alters extracellular catecholamine levels [45] has been shown to improve performance on the CANTAB DMTS task, but not on the spatial working memory task in children with ADHD $[33,46,47]$. It has been proposed that the therapeutic effect of methylphenidate is mediated through the enhancement of tonic rather than phasic dopamine release [45]. Therefore the DMTS task in ADHD may show sensitivity both to treatments that alter tonic prefrontal dopamine levels and to variation in COMT genotype. Further work is needed to fully characterize the specific aspects of DMTS task performance that are related to COMT genotype. Many of the commonly used measures of working memory, such as the n-back task and the Wisconsin Card Sorting Task, confound in time both the requirement for stable and flexible representations, and the working memory sub-process (be it encoding, maintenance, or retrieval) being engaged. Selection of tasks that allow for the compartmentalization of these processes will help in disentangling the relationship between COMT genotype and neurocognitive functioning in ADHD.

The finding that impaired performance on the DMTS was associated with the val rather than the met allele in children with ADHD supports previous research showing an association between poorer performance on executive tasks and the val allele in both healthy adults $[18,19]$ and children [20]. Only a few previous studies have specifically explored the relationship between COMT genotype and cognitive abilities in ADHD 
populations, with results conflicting. Two studies found no relationship between COMT genotype and executive function in children with ADHD [22,23], while Bellgrove et al. [24] found that the met rather than the val variant was associated with impaired sustained attention performance in children with ADHD. There are a number of participant-factors that may influence the finding of a relationship between COMT genotype and executive function in children with ADHD, including history of medication and participant age. Perhaps more importantly, given the nature of the findings of the present study, it may be that cognitive task selection is also critically important.

The current study imposed a stringent correction for multiple comparisons that accounted both for the number of tasks studied and the number of SNPs and genetic models tested. The observation that the recessive model of the val allele survived this correction is interesting in light of other studies that have also reported recessive effects. For example, among children with ADHD val/ val homozygotes have impaired task oriented performance [48] and increased antisocial behaviour [49] relative to carriers of at least one met allele. Nevertheless, we note that a nominally significant effect of the additive model $(p=0.039)$ was also found that might survive multiple comparison testing in larger samples. We repeated our analysis in just the sub-sample of participants who were medication free on the day of test (covarying for gender, age, and IQ). Although this analysis did not survive correction for multiple comparisons it was nonetheless nominally significant $(p=0.02)$.

Since we failed to observe a relationship between COMT genotype and performance on either the SP or SWM tasks, one may conclude that performance on these tasks is perhaps influenced by other catecholamine gene variants. Nevertheless, we also failed to find evidence of association between performance on the working memory tasks and allelic variation in any of the other catecholamine genes (NET1, DRD2, DBH, DRD4) under study. There are however, a number of methodological considerations that should be considered. First, it should be noted that the low minor allele frequency associated with a number of the catecholamine SNPs may have reduced our power to detect significant associations in the relatively small sample size under study. Second, the three working memory tests used in this study were not matched for psychometric characteristics or task difficulty. In addition, although all our analyses co-varied for the medication status of the participants, it is possible that medication-related factors may have obscured associations between the catecholamine gene variants and working memory measures. The sample of children with ADHD presented here was recruited from a hospital service that specialized in assessment of children with severe behavioural disturbances and as such they presented with a high rate of conduct disorder co-morbidity. Previous research has demonstrated that the association between COMT val/val genotype and ADHD is modified by coexisting extreme anti-social behaviour and conduct disturbances [49]. However, Langley et al. [50] investigated whether impaired social functioning or executive control mediated the relationship between COMT and anti-social behaviour in the context of children with ADHD. Their analysis revealed a mediating effect of social but not executive functioning, suggesting that the association between COMT genotype and working memory ability reported herein is unlikely to be mediated by co-morbid conduct disturbance.

\section{Conclusion}

In summary, the results of the present study indicate that in children with ADHD the val variant of the COMT gene polymorphism is associated with impaired performance on a DMTS task that requires the stable maintenance of representations in working memory, but not with performance on working memory tasks that additionally require the dynamic updating of information. Although it remains uncertain whether the val allele of the COMT genotype confers susceptibility to ADHD, our results suggest that this polymorphism is associated with working memory impairments in ADHD children. The association between COMT genotype and working memory impairment may have important functional significance for ADHD, given that the latter has been reliably linked to poor educational and clinical outcomes.

\section{Additional file}

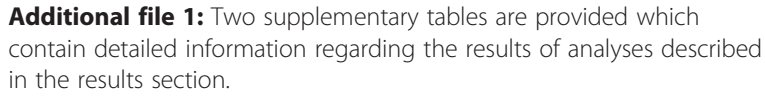

M.A. Bellgrove has received reimbursement from Lilly Pharmaceuticals and Jansen Cilag for conference travel expenses and for speaking at conferences unrelated to the content of this manuscript. M.A. Bellgrove is also the recipient of research funding from Lilly Pharmaceuticals for work unrelated to this manuscript. All other authors report no conflicts of interest to declare.

\section{Acknowledgments}

The authors would like to acknowledge the assistance of Ms Karen Dally and Dr Ziarah Hawi. This work was supported by grants from National Health and Medical Research Council (NHMRC) of Australia to MAB, RHW, and AV and from a NARSAD Young Investigator Award to MAB. MAB receives Research Fellowship support under a Career Development Award from the NHMRC, Australia.

\section{Author details}

${ }^{1}$ The University of Queensland, Queensland Brain Institute and School of Psychology, St Lucia 4072 Brisbane, Australia. ${ }^{2}$ Academic Child Psychiatry Unit, Department of Paediatrics, University of Melbourne, Royal Children's 
Hospital, Parkville, Australia. 'Bruce Lefroy Centre, Murdoch Children's Research Institute, Parkville, Australia. ${ }^{4}$ The University of Queensland, Queensland Brain Institute, Brisbane, Australia. ${ }^{5}$ The University of Queensland, School of Chemistry and Molecular Biosciences, Brisbane, Australia.

\section{Authors' contributions}

NM and TDRC performed statistical analysis. NM drafted the manuscript. AV participated in study design and in drafting the manuscript. JW, AP, and PL performed the genotyping. AM and JY performed the clinical assessments. RHW participated in the development of the study with particular contribution to the selection of genetic targets. MAB conceived of the study and helped draft the manuscript. All authors read and approved the final manuscript.

Received: 13 July 2011 Accepted: 28 May 2012

Published: 28 May 2012

\section{References}

1. American Psychiatric Association: Diagnostic and statistical manual of mental disorders, (4th Edn). Wasington DC: American Psychiatric Association; 1994.

2. Polanczyk G, de Lima MS, Horta BL, Biederman J, Rohde LA: The worldwide prevalence of ADHD: a systematic review and metaregression analysis. Am J Psychiatry 2007, 164:942-948.

3. Frazier TW, Youngstrom EA, Glutting JJ, Watkins MW: ADHD and achievement: Meta-analysis of the child, adolescent, and adult literatures and a concomitant study with college students. J Learn Disabil 2007, 40:49-65.

4. Faraone SV, Sergeant J, Gillberg C, Biederman J: The worldwide prevalence of ADHD: Is it an American condition? World Psychiatry 2003, 2:104-113.

5. Castellanos FX, Tannock R: Neuroscience of attention-deficit/hyperactivity disorder: the search for endophenotypes. Nat Rev Neurosci 2002, 3:617628.

6. Ando J, Ono Y, Wright MJ: Genetic structure of spatial and verbal working memory. Behav Genet 2001, 31:615-624.

7. Martinussen R, Hayden J, Hogg-Johnson S, Tannock JA: A meta-analysis of working memory impairments in children with attention-deficit/ hyperactivity disorder. J Am Acad Child Adolesc Psychiatry 2005, 44:377384

8. Baddeley A: Working memory: Looking back and looking forward. Nat Rev Neurosci 2003, 4:829-839

9. Packiam Alloway T, Gathercole SE, Elliott J: Examining the link between working memory behaviour and academic attainment in children with ADHD. Dev Med Child Neurol 2010, 52:632-636.

10. Owen AM, McMillian MK, Laird AR, Bullmore E: N-back working memory paradigm: a meta-analysis of normative functional neuroimaging studies. Hum Brain Mapp 2005, 25:46-59.

11. Wager TD, Smith EE: Neuroimaging studies of working memory: a metaanalysis. Cogn Affect, \& Behav Neurosci 2003, 3:255-274.

12. Curtis $C E$, D'Espositio M: Persistent activity in the prefrontal cortex during working memory. Trends Cogn Sci 2003, 7:415-423.

13. Arnsten AF, Li B-M: Neurobiology of executive functions: catecholamine influences on prefrontal cortical function. Biol Psychiatry 2005, 57:13771384.

14. Vijayraghavan S, Wang M, Birnbaum SG, Williams GV, Arnsten AF: Inverted$U$ dopamine $D 1$ receptor actions on prefrontal neurons engaged in working memory. Nat Neurosci 2007, 10:376-384.

15. Meyer-Lindenberg A, Nichols T, Callicott JH, Ding J, Kolachana B, Buckholtz J, Mattay VS, Egan M, Weinberger DR: Impact of complex genetic variation in COMT on human brain function. Mol Psychiatry 2006, 11:867-877.

16. Lachman HM, Papolos DF, Saito T, Yu YM, Szumlanski CL, Weinshilboum RM: Human catechol-O-methyltransferase pharmacogenetics: description of a functional polymorphism and its potential application to neuropsychiatric disorders. Pharmacogenetics 1996, 6:243-250.

17. Egan MF, Goldberg TE, Kolachana BS, Callicott JH, Mazzanti CM, Straub RE, Goldman D, Weinberger DR: Effect of COMT Val108/158 Met genotype on frontal lobe function and risk for schizophrenia. Proc Natl Acad Sci USA 2001, 98:6917-6922.

18. Barnett JH, Jones PB, Robbins TW, Muller U: Effects of the catecholOmethyltransferase Val158Met polymorphism on executive function: a meta-analysis of the Wisconsin Card Sort Test in schizophrenia and healthy controls. Mol Psychiatry 2007, 12:502-509.
19. Malhotra AK, Kestler LJ, Mazzanti CM, Bates JA, Goldberg TE, Goldman D: A functional polymorphism in the COMT gene and performance on a test of prefrontal cognition. Am J Psychiatry 2002, 159:652-654.

20. Diamond D, Biriand L, Fosella J, Gehlbach L: Genetic and neurochemical modulation of prefrontal cognitive functions in children. Am J Psychiatry 2004, 161:125-132

21. Cheuk D, Wong V: Meta-analysis of association between a catechol-Omethyltransferase gene polymorphism and attention deficit hyperactivity disorder. Behav Genet 2006, 36:651-659.

22. Tarek E, Grizenko N, Ben Amor L, Lageix P, Mbekou V, Deguzman R, Torkaman-Zehi A, Stepanian T, Baron C, Joober R: CatecholOmethyltransferase (COMT) Val108/158Met polymorphism does not modulate executive function in children with ADHD. BMC Med Genet 2004, 5:30

23. Mills S, Langley K, Van Der Bree M, Street E, Turic D, Owen MJ, O'Donovan $M C$, Thapar A: No evidence of association between catechol-Omethyltransferase (COMT) Val158Met genotype and performance on neuropsychological tasks in children with ADHD: a case-control study. BMC Psychiatry 2004, 4:15.

24. Bellgrove MA, Domschke K, Hawi Z, Kirley A, Mullins C, Robertson IH, Gill M: The methionine allele of the COMT polymorphism impairs prefrontal cognition in children and adolescents with ADHD. Exp Brain Res 2005, 163:352-360.

25. Seamans JK, Yang CR: The principal features and mechanisms of dopamine modulation in the prefrontal cortex. Prog Neurobiol 2004, 74:157.

26. Gizer IR, Ficks C, Waldman ID: Candidate gene studies of ADHD: a metaanalytic review. Hum Genet 2009, 126:51-90.

27. Silverman WK, Albano AM: The anxiety disorders interview schedule for children for DSM-IV (child and parent versions). San Antonio, TX: Psychological Corporation; 1996.

28. Conners CK: Conners' Rating Scales - Revised. Toronto, ON: Multi-Health Systems Inc;; 1997

29. Achenbach T: Manual for the Teacher's Report Form and profile. Burlington, VT: Department of Psychiatry, University of Vermont; 1991.

30. Wechsler D: Wechsler Intelligence Scale for Children-Fourth Edition. Administration and scoring manual. San Antonio, TX: Harcourt Assessment, Inc; 2003.

31. Taylor E, Schachar R, Thorley G, Wieselberg M: Conduct disorder and hyperactivity: 1 . separation of hyperactivity and antisocial conduct in British child psychiatric patients. Br J Psychiatry 1986, 149:760-767.

32. Wilkinson GS: WRAT-3: Wide Range Achievement Test-3 administration manual. Wilmington, DE: Wide Range; 1993.

33. Rhodes SM, Coghill DR, Matthews K: Methylphenidate restores visual memory, but not working memory function in attention deficithyperkinetic disorder. Psychopharmacology 2004, 175:319-330.

34. Need AC, Attix DK MMJ, CE T, Linney KL, Hunt P, Ge D, Heinzen EL, Maia JM, Shianna KV, et al: A Genome-wide study of common SNPs and CNVs in cognitive performance in the CANTAB battery. Hum Mol Genet 2009, $18: 4650-4661$

35. Daly G, Hawi Z, Fitzgerald M, Gill M: Mapping susceptibility loci in attention deficit hyperactivity disorder: Preferential transmission of parental alleles at DAT1, DBH and DRD5 to affected children. Mol Psychiatry 1999, 4:192-196.

36. Bellgrove MA, Hawi Z, Gill M, Robertson IH: The cognitive genetics of attention deficit hyperactivity disorder (ADHD): Sustained attention as a candidate endophenotype. Cortex 2006, 42:838-845.

37. Tang Y, Buxbaum SG, Waldman I, Anderson GM, Zaetian CP, Kohnke MD, Cubells JF: A single nucleotide polymorphism at DBH, possibly associated with attention-deficit/hyperactivity disorder, associates with lower plasma dopamine beta-hydroxylase activity and is in linkage disequilibrium with two putative functional single nucleotide polymorphisms. Biol Psychiatry 2006, 60:1034-1038.

38. Kollins SH, Anastopoulos AD, Lachiewicz AM, Fitzgerald D, Morrissey-Kane E, Garrett ME, Keatts SL, Ashley-Koch AE: SNPs in dopamine D2 receptor gene (DRD2) and norepinephrine transporter gene (NET) are associated with continuous performance task (CPT) phenotypes in ADHD children and their families. Am J Med Genet B Neuropsychiatr Genet 2008, 147B (8):1580-1588

39. Bellgrove MA, Hawi Z, Lowe N, Kirley A, Robertson IH, Gill M: DRD4 gene variants and sustained attention in Attention Deficit Hyperactivity 
Disorder (ADHD): Effects of associated alleles at the VNTR and -521 SNP. Am J Med Genet B Neuropsychiatr Genet 2005, 136(1):81-86.

40. Churchill GA, Doerge RW: Empirical threshold values for quantitative trait mapping. Genet 1994, 138:963-971.

41. Doerge RW, Churchill GA: Permutation tests for multiple loci affecting a quantitative character. Genet 1996, 142:285-294.

42. Westfall P, Young S: Resampling-Based Multiple Testing: Examples and Methods for $p$-value Adjustment. New York: Wiley; 1993.

43. Bruder GE, Keilp JC, Xu H, Shikhman M, Schori F, Gorman JM, Gilliam TC: Catechol-O-Methyltransferase (COMT) genotypes and working memory: Associations with differing cognitive operations. Biol Psychiatry 2005, 58:901-907.

44. Bilder RM, Volavka J, Lachman HM, Grace AA: The catechol-omethyltransferase (COMT) polymorphism: Relations to tonic-phasicdopamine hypothesis and neuropsychiatric phenotypes. Neuropsychopharmacology 2004, 29:1943-1961.

45. Volkow ND, Wang G, Fowler JS, Logan J, Gerasimov M, Maynard L, Ding Y, Gatley SJ, Gifford A, Franceschi D: The therapeutic doses of oral methylphenidate significantly increases extracellular dopamine in the human brain. J Neurosci 2001, 21:RC121.

46. Coghill DR, Rhodes SM, Matthews K: The neuropsychological effects of chronic methylphenidate on drug-naive boys with attention deficit/ hyperactivity disorder. Biol Psychiatry 2007, 62:954-962.

47. Rhodes SM, Coghill DR, Matthews K: Acute neuropsychological effects of methylphenidate in stimulant drug-naive boys with ADHD II: Broader executive and non-executive domains. J Child Psychology and Psychiatry 2006, 47:1184-1194.

48. Sengupta S, Grizenko N, Schmitz N, Schwartz G, Bellingham J, Polotskaia A, Stepanian MT, Goto Y, Grace AA, Joober R: COMT Val108/158Met Polymorphism and the modulation of task-oriented behavior in children with ADHD. Neuropsychopharmacology 2008, 33:3069-3077.

49. Caspi A, Langley K, Milne B, Moffitt TE: A replicated molecular genetic basis for subtyping antisocial behavior in children with Attention-Deficit/ Hyperactivity Disorder. Arch Gen Psychiatry 2008, 65(2):203-210.

50. Langley K, Heron J, O' Donovan MC, Owen MJ, Thapar A: Genotype link with extreme antisocial behavior: the contribution of cognitive pathways. Arch Gen Psychiatry 2010, 67(12):1317-1323.

doi:10.1186/1744-9081-8-25

Cite this article as: Matthews et al:: The COMT Val158 allele is associated with impaired delayed-match-to-sample performance in ADHD.

Behavioral and Brain Functions 2012 8:25.

\section{Submit your next manuscript to BioMed Central and take full advantage of:}

- Convenient online submission

- Thorough peer review

- No space constraints or color figure charges

- Immediate publication on acceptance

- Inclusion in PubMed, CAS, Scopus and Google Scholar

- Research which is freely available for redistribution 